\title{
The Metabolic Cardiorespiratory Effects of Abdominal Electrical Muscle Stimulation
}

\author{
Craig E Broeder ${ }^{1 *}$, Amanda J Salacinski ${ }^{2}$, Steve Mauk ${ }^{2}$ and Dimitria Vandarakis ${ }^{1}$ \\ ${ }^{1}$ Exercising Nutritionally, Northern Illinois University, USA
}

${ }^{2}$ Department of Kinesiology and Physical Education, Northern Illinois University, USA

*Corresponding author: Craig E Broeder, PH.D. FACSM, FNAASO, Exercising Nutritionally, LLC, 1943 Phaeton Court, Naperville, IL 60565, USA, Tel: 630-303-3686, Fax:630-547-0056, E-mail: en.Ilc@me.com

\begin{abstract}
Electrical Muscle Stimulation (EMS) has been studied in athletes, healthy, and diseased populations mainly focusing on muscle strength and body composition. Therefore, the purpose of this study was to determine the metabolic and cardiovascular effects of acute EMS at rest and steady-state walking (3.5 mph \& $5 \%$ grade) in healthy adults. Thirty-eight subjects $(\mathrm{M}=19, \mathrm{~F}=19)$ volunteered and completed resting and steady-state exercise trials with and without EMS in duplicate on separate days (test-retest reliability). Energy Expenditure $(\mathrm{EE})$, Ventilation $\left(\mathrm{V}_{\mathrm{E}}\right)$, respiration rate, tidal volume, $\mathrm{VO}_{2}, \mathrm{VCO}_{2}, \mathrm{RER}, \mathrm{HR}$ \% \%at, \%Carbohydrate (CHO), and fat and $\mathrm{CHO}$ grams were measured. Test-retest results showed no significant trial differences with very strong ICC $r$-values $(\geq 0.90)$ and low SEEs at rest or during exercise for both the shame and treatment conditions. At rest, EMS activation increased $\mathrm{EE}=19.4 \%, \mathrm{VO}_{2}=17.4 \%$, and $\mathrm{HR}=14.3 \%$ ( $\mathrm{p}$-value $=0.0001)$. During exercise, $\mathrm{V}_{\mathrm{E}}=9.6 \%, \mathrm{EE}=4.4 \%, \mathrm{VO}_{2}$ $=4.6 \%$, and $\mathrm{HR}=8.3 \%$ increased ( $p$-value $=0.0001)$. Male and females responded similarly, and the effect EMS activation had on $\mathrm{EE}$ and $\mathrm{VO}_{2}$ were independent of a person's maximal EMS activation tolerance level (i.e., low versus high tolerance level). Fat-free weight ( $r$-square $=0.78, p$-value $=0.0001)$ and trunk lean tissue $(r$-square $=0.79, p$-value $=$ $0.0001)$ were the strongest step-wise regression correlates with baseline EE. EMS activation significantly increased the metabolic and cardiorespiratory responses in men and women at rest and walking at steady-state $\left(50 \% \mathrm{VO}_{2}\right.$ max $)$.
\end{abstract}

\section{Keywords}

e-Stim, Metabolism, Energy expenditure

\section{Introduction}

Surface Electrical Muscle Stimulation (EMS) is the excitation of muscle through electrodes directly placed on the skin of a given target muscle or muscle groups. Past studies have investigated the effects of EMS in healthy subjects or special populations, e.g., spinal cord injury, diabetic or heart failure patients [1-5]. Additionally, other studies have focused on muscle strength, speed, power, co-contraction effects, abdominal strength, body composition, and Energy Expenditure (EE) [6-13].

In a study by Porcari, et al. [8], they showed eight weeks of EMS training placed over the abdominal wall significantly improved abdominal strength $58 \%$ compared to no improvements in the control group. Muscle endurance increased $100 \%$ compared to a $28 \%$ increase in the control group, and self-perceived muscle tone was reported to increase in $100 \%$ of the subjects tested [8]. This same study showed a $3.6 \mathrm{~cm}$ decrease in waist circumference in the EMS group and no significant change in the control group. These results suggest that the training stimulation provided was adequate for both chronic neuromuscular and metabolic adaptations and is supported by other studies [8,9,14-18].

Prolonged EMS training improved strength, aerobic capacity, and functional movement in adults $[14,19,20]$. For example, in a 14-week cross over design study where the EMS training intensity was set so that Heart Rate Reserve (HRR) was between $55-90 \%$, maximal effort treadmill walking time, peak oxygen consumption $\left(\mathrm{VO}_{2 \text { peak }}\right)$, 6-min walking distance, and quadricep strength significantly improved in healthy sedentary adults compared to both baseline and control measurements [14].

More recently, Crowe and Caufield [21] examined

Citation: Broeder CE, Salacinski AJ, Mauk S, Vandarakis D (2018) The Metabolic Cardiorespiratory Effects of Abdominal Electrical Muscle Stimulation. Int J Sports Exerc Med 4:087. doi.org/10.23937/24695718/1510087

Received: November 30, 2017; Accepted: April 23, 2018; Published: April 25, 2018

Copyright: (C) 2018 Broeder CE, et al. This is an open-access article distributed under the terms of the Creative Commons Attribution License, which permits unrestricted use, distribution, and reproduction in any medium, provided the original author and source are credited. 
voluntary contraction versus EMS stimulated exercise during different conditions. They showed EMS activation could produce comparable max heart rates, voluntary EMS assisted maximal cycle ergometry produced a greater oxygen uptake (Voluntary Exercise = $52 \mathrm{ml}$ / $\mathrm{kg} / \mathrm{min}, \mathrm{EMS}=39 \mathrm{ml} / \mathrm{kg} / \mathrm{min}$ ). Additionally, immediately following the maximal exercise burst, greater EPOC responses were observed with voluntary exercise (Voluntary Exercise $=110.5 \mathrm{kcal}, \mathrm{EMS}=96.5 \mathrm{kcal})$. Finally, comparing the fatigue responses during the voluntary steady-state exercise at $65 \%$ of max heart rate, despite a similar exercise heart rate and oxygen uptake response, the subject fatigued quicker during the voluntary unassisted versus EMS assisted based exercise (Voluntary Exercise $=4 \mathrm{hrs}, \mathrm{EMS}=6 \mathrm{hrs}$ ).

Several commercial EMS companies have advertised that the use of abdominal EMS stimulator belts improve core muscle strength, endurance, and may improve abdominal muscle tone or leanness. To date, no research study has specifically determined what the metabolic and cardiorespiratory effects of abdominal EMS has at rest or during exercise are while using both a shame treatment (or control trial) and test-retesting verification of the results. Thus, the purpose of this study was to determine the metabolic and cardiorespiratory effects produced by an acute abdominal EMS stimulation protocol during standardized resting conditions and in conjunction with steady-state walking at $3.5 \mathrm{mph}$ up a $5 \%$ grade on oxygen consumption, substrate utilization, and cardiorespiratory demand. The study designed included test-retest measurements on all variables of interest, a shame intervention control trial, and was monitored by an independent FDA approval monitoring company (Libra Medical).

\section{Methods}

Forty-three healthy male and female subjects ages 18 to 45-years-old volunteered for the study. Thirty-eight (Males $=19$, Females $=19$ ) subjects completed all required study procedures. For those subjects not completing the study; one subject dropped out due to an unrelated sport injury, two subjects changed jobs and had scheduling conflicts; one subject dropped out and provided no reason; and the principal investigator dropped one subject due to extremely poor cardiovascular fitness and could not complete the baseline protocols. Each subject performed the following items: A pretesting orientation meeting, IRB approved consent form explanation, a health and physical activity questionnaire; a Block short-form standardized food frequency questionnaire (Nutrition Quest, Berkeley, CA), a body composition assessment, a free-living physical activity assessment, a graded exercise treadmill test for the determination of maximal aerobic capacity, a practice EE measurement trial, an EMS accommodation training session, and two EE trials with and without EMS (for a total of four trials). The EE trials with and without
EMS were performed in duplicate (Trials A \& B) on all subjects to assure accurate data collection and account for day-to-day subject variability and possibly subject EMS response adaptations, i.e., repeated EMS use can lead to a lower perceived stimulus load that might affect a person's physiological response to a given EMS activation level.

\section{Baseline assessments}

Weight and body composition was measured using an advanced segmental multi-frequency InBody 520 bioelectrical impedance system (Los Angeles, California). Each subject was asked to follow a pretesting standardized protocol including no intense exercise on the day of measurement, ensuring they were adequately hydrated by drinking 16 ounces of water four hours prior to the measurement, and voiding immediately prior to the subject's measurement.

Subjects performed an exercise treadmill test to maximal effort using a standardized protocol for healthy adults [22]. The maximal cardiorespiratory data included; max Heart Rate (max HR), max Ventilation ( $\left.V_{E} \max \right)$, maximal oxygen uptake $\left(\mathrm{VO}_{2 \text { max }}\right)$, and maximal Respiratory Exchange Ratio (RER max). Subjects were encouraged to give their best effort and the following criteria were used to assure a valid test; reaching a HR $\pm 10 \mathrm{bpm}$ of each subject's age predicted max heart rate, RER $\geq 1.10$, and an increase oxygen uptake $\leq 1-2 \mathrm{ml} / \mathrm{kg} / \mathrm{min}$ despite an increase in either treadmill speed or grade $[23,24]$. Subjects not achieving two of the three maximal effort criteria were retested. Only one subject needed to be retested for not meeting two of the three criteria.

\section{The EMS system}

The CONTOUR MX9 (Contour, Minneapolis, MN) muscle stimulator was used. The CONTOUR MX9 has five built-in programs. In the current study, the muscular strength program was used at level $3(85 \mathrm{~Hz})$ to assure type I, type IIA, and type IIx muscle fiber activation [12]. The CONTOUR MX9 unit set at strength level 3 produced a contraction frequency $=85 \mathrm{~Hz}$ for 6-secs with a recovery frequency $=10 \mathrm{~Hz}$ for 4 -secs.

\section{Practice energy expenditure and EMS accommo- dation training sessions}

Prior to starting the EE measures with and without EMS trials, each subject was familiarized with the testing process and to assure the person could tolerate EMS goal stimulation level (EMS \% of unit activation level $\geq$ $15 \%$ of units max output). Subject's followed the same instructions and measurement process that would be used in the actual test trials. During the training session, a coded HR band was placed on each person along with an EMS abdominal stimulation belt. Additionally, a pulse oximeter with HR measurement system was placed on the index finger of each subject as a secondary measure of $\mathrm{HR}$ with and without EMS activation. 
At the start of the practice session, EE with the Contour MX9 belt worn but without EMS stimulation (shame trial) was measured as described below using a Quark CPET RMR canopy dilution system by COSMED (Chicago, IL). After the shame EE measurements were completed, the EMS abdominal stimulation belt was activated. At start-up, the EMS unit automatically sets the activation level to $10 \%$ of the maximal unit output level. The activation level was set to the highest tolerable percentage of the maximum unit output ( 55 volts). Subjects were instructed to lay as still as possible while allowing the CONTOUR MX9 unit to initiate and perform all of the abdominal core muscle work. If a subject could not achieve a minimum activation level of $15 \%$ of max output, an additional training session was scheduled until they could reach the minimum EMS level. All subjects in this study exceeded the minimum target activation levels required for the metabolic measurement trials. After this intensity value was established, it was recorded and remained consistent throughout the entire testing period and between trials.

\section{Baseline energy expenditure measurements with and without EMS trials}

Energy expenditure measurements were performed with and without EMS in duplicate on separate days. Subjects were instructed to refrain from food, caffeine, energy drinks, and nicotine products for a minimum of four hours prior to testing. Subjects were also asked to avoid intense exercise 12 hours prior to testing. To minimize diurnal variations, subjects were retested \pm 90 minutes within the initial test trial time. To verify pre-physical activity control requirements were maintained, subject's wore a research grade SenseWear activity armband (BodyMedia, Pittsburgh, PA) and were monitored 24 hours prior to and during each person's respective measurement trials. Upon completion of the subject's trial, activity data was uploaded into the BodyMedia research data analysis program (Version 7.0). Data recorded included each person's total daily $\mathrm{EE}$, number of steps, sedentary minutes (<3.0 METS), moderate activity (3.0-6-0 METs), vigorous activity (6.09.0 METs), and very vigorous activity (>9.0 METs). These data are reported as a 24-hour daily average and percentage of the total EE per day.

The placement of the abdominal belt was standardized so the center horizontal and vertical aspect of the belt was placed directly at the umbilical site. New EMS pads were used for each person's measurement trial. Each subject laid at rest on his or her back on a padded table with legs slightly elevated by a leg support pillow. After a 15-minute premeasurement rest period, a ventilatory hood was placed over the subject's head for an additional 15 minutes prior to starting the data measurement period and the lab lights were dimmed with a night light for the entire testing period. The ventilatory flow rate was adjusted so optimum oxygen and carbon dioxide concentrations existed in the hood enclosure for accurately measuring the baseline energy expenditure according to manufacturer guidelines. We have shown previously in 30 subjects using identical measurement procedures, the test-retest reliability flow rate between trial differences in liters per minute was just $0.7 \%$ at resting hood flow rates, $\mathrm{VO}_{2}(\mathrm{ml} / \mathrm{min} / \mathrm{kg})$ and resting energy expenditure (kcal/day) was $5 \mathrm{ml}$ (1.9\% between trial difference) and $16 \mathrm{kcal}$ ( $0.9 \%$ between difference), respectively [10]. Breath-by-breath metabolic measurements were made using a Cosmed Quark CEPT metabolic hood system.

Baseline EE with the Contour MX9 belt on but no EMS activation (Shame treatment) was measured for 20 minutes. During the 20-minute baseline measurement period, 0-5 mins were used as a washout period; and minutes 6-20 were used as the baseline steady-state $\mathrm{EE}$ measurement period. Immediately following the shame treatment period, the EMS activation trial began for an additional 20-minutes following the same data collection process under the shame condition.

Baseline metabolic test-retest verification, if a subject's between baseline steady-state $\mathrm{VO}_{2}$ measurements values exceeded $25 \mathrm{mls}$, a third trial was performed. The two closest means, provided they were $<$ the $25 \mathrm{ml}$ criterion value were used in the data analyses. Four subjects required a third baseline energy expenditure verification measurement trial day.

\section{Steady-State exercise cardiorespiratory measure- ment with and without EMS trials}

Immediately after each subject completed the resting EE measurement, each subject performed the exercise trials with and without EMS activation, using Cosmed's Quark CPET breath-by-breath face mask. Prior to starting exercise, the system was calibrated for ventilation, $\%$ oxygen, and \% carbon dioxide measurements as recommended by the manufacturer. After subject preparation, each subject stood quietly on the treadmill for five minutes (pre-exercise washout period) as his or her $V_{E^{\prime}}$ $\mathrm{VO}_{2}, \mathrm{RER}$, and HR were monitor to assure appropriate pre-exercise values (i.e., HR $<100 \mathrm{bpm}$ or RER $\leq 0.85$ ).

Subjects were then asked to walk for 20 minutes on a treadmill at $3.5 \mathrm{mph}$ up a $5 \%$ grade wearing the Contour MX9 belt but not activated for the shame treatment. Again, the first five minutes were used as a washout period and minutes 6-20 used as the steady-state shame measurement period. Immediately following, the EMS activation trial continued for an additional 20 minutes following the measurement process as the shame exercise condition. The measurement variables during the shame and EMS exercise trials included $V_{E}(L)$, respiration rate (BPM), tidal volume $(\mathrm{L}), \mathrm{VO}_{2}(\mathrm{ml} / \mathrm{kg} / \mathrm{min})$, $\mathrm{VCO}_{2}(\mathrm{ml} / \mathrm{kg} / \mathrm{min}), \operatorname{RER}\left(\mathrm{VOC}_{2} / \mathrm{VO}_{2}\right)$, energy expenditure (kcal/min), HR (BPM), \% fat, \% CHO, fat grams, and $\mathrm{CHO}$ grams. All data collected were filtered so that the 
Table 1: Subject's aerobic fitness profile.

\begin{tabular}{|c|c|c|c|c|}
\hline Variable & All Subjects $(n=38)$ & Males $(n=19)$ & Females $(\mathrm{N}=19)$ & Gender Comparison \\
\hline Age (yrs) & $27.9 \pm 6.9$ & $26.0 \pm 4.8$ & $29.8 \pm 8.3$ & NS \\
\hline Ve max (liters $\left.\cdot \min ^{-1}\right)$ & $119.8 \pm 36.6$ & $146.8 \pm 30.7$ & $92.8 \pm 16.69$ & $p=0.0001$ \\
\hline $\mathrm{VO}_{2} \max \left(\right.$ liters $\left.\cdot \mathrm{min}^{-1}\right)$ & $3.346 \pm 0.990$ & $4.124 \pm 0.790$ & $2.568 \pm 0.360$ & $p=0.0001$ \\
\hline $\mathrm{VO}_{2} \max \left(\mathrm{ml} \cdot \mathrm{kg}^{-1} \cdot \mathrm{min}^{-1}\right)$ & $44.0 \pm 8.3$ & $47.8 \pm 7.8$ & $40.3 \pm 7.0$ & $p=0.0033$ \\
\hline METS max & $12.6 \pm 2.4$ & $13.7 \pm 2.2$ & $11.5 \pm 2.0$ & $p=0.0033$ \\
\hline $\mathrm{RER} \max \left(\mathrm{VCO}_{2} / \mathrm{VO}_{2}\right)$ & $1.18 \pm 0.06$ & $1.20 \pm 0.05$ & $1.17 \pm 0.07$ & NS \\
\hline Max HR (bpm) & $184.9 \pm 13.6$ & $186.84 \pm 10.9$ & $182.8 \pm 16.2$ & NS \\
\hline$\%$ of Predicted Max $\mathrm{HR}^{\dagger}$ & $98.1 \pm 6.8$ & $98.4 \pm 5.4$ & $97.7 \pm 8.1$ & NS \\
\hline
\end{tabular}

liters $•$ minute $=$ liters per minute; $\left(\right.$ Means \pm SD); ${ }^{\dagger}$ - Predicted Max heart Rate $($ Tanaka, et al. 2001 [25]; Max Heart Rate = 208-0.7 $x$ age).

Table 2: Subject's Body Composition Profile.

\begin{tabular}{|c|c|c|c|c|}
\hline Variable & All Subjects $(n=38)$ & Males $(n=19)$ & Females $(\mathrm{N}=19)$ & Gender Comparison \\
\hline Weight (kg) & $76.4 \pm 17.0$ & $86.8 \pm 13.3$ & $66.0 \pm 13.6$ & $p=0.0001$ \\
\hline Height (meters) & $1.74 \pm 0.10$ & $1.82 \pm 0.06$ & $1.66 \pm 0.07$ & $p=0.0001$ \\
\hline $\mathrm{BMI}\left(\mathrm{Wt} / \mathrm{Ht}^{2}\right)$ & $25.0 \pm 3.7$ & $26.1 \pm 3.2$ & $23.9 \pm 4.0$ & $p=0.07$ \\
\hline Body Fat (\%) & $21.2 \pm 8.7$ & $16.6 \pm 7.3$ & $25.7 \pm 7.7$ & $p=0.0007$ \\
\hline Fat Weight (kg) & $16.2 \pm 8.2$ & $17.7 \pm 8.9$ & $14.7 \pm 7.3$ & NS \\
\hline Fat-Free Weight (kg) & $60.2 \pm 15.2$ & $72.2 \pm 2.1$ & $48.3 \pm 6.2$ & $p=0.0001$ \\
\hline Intracellular Water (kg) & $27.7 \pm 7.1$ & $33.2 \pm 5.4$ & $22.1 \pm 2.8$ & $p=0.0001$ \\
\hline Extracellular Water (kg) & $16.4 \pm 4.1$ & $19.6 \pm 3.1$ & $13.2 \pm 1.7$ & $p=0.0001$ \\
\hline RA-LA ${ }^{\dagger}$ Lean $(\mathrm{kg})$ & $6.9 \pm 2.4$ & $8.8 \pm 1.8$ & $5.0 \pm 1.0$ & $p=0.0001$ \\
\hline Trunk Lean (kg) & $26.9 \pm 6.9$ & $32.3 \pm 5.0$ & $21.4 \pm 3.0$ & $p=0.0001$ \\
\hline RL-LL† Lean (kg) & $18.1 \pm 4.3$ & $5.0 \pm 1.0$ & $14.6 \pm 2.2$ & $p=0.0001$ \\
\hline Right Arm \% of Lean & $116.2 \pm 12.5$ & $119.8 \pm 14.2$ & $112.7 \pm 9.6$ & NS \\
\hline Left Arm \% of Lean & $111.2 \pm 21.1$ & $111.6 \pm 28.3$ & $111.0 \pm 10.5$ & NS \\
\hline Trunk \% of Lean & $108.7 \pm 7.3$ & $111.0 \pm 8.7$ & $106.7 \pm 5.1$ & 0.07 \\
\hline Right Leg $\%$ of Lean & $105.4 \pm 7.2$ & $106.8 \pm 1.6$ & $103.9 \pm 1.6$ & NS \\
\hline Left Leg $\%$ of Lean & $104.7 \pm 6.8$ & $105.6 \pm 6.9$ & $103.9 \pm 6.8$ & NS \\
\hline
\end{tabular}

$\dagger$ - RA-LA and RL-LL represent the sum of lean tissue in $\mathrm{kg}$ for the right and left arms or legs, respectively (Means \pm SD).

breath-by-breath values were averaged into five-minute periods excluding the initial 5-min wash-out and 5-min EMS ramping periods. The exercise data were analyzed using four measurement periods; 0-5, 6-10, 11-15, and the over-all trial mean (0-15 mins).

\section{Statistical procedures}

All data collected was verified by an independent FDA approved monitoring company auditor team (Libra Medical, MN). Test-retest statistics were performed on the 15-minute mean data for baseline resting EE and steady-state exercise, respectively. Because there were no statistically significant differences in any key variables measured between the repeat trials, the means of Trial A and Trial B under each condition (shame repeat comparisons versus EMS activation repeat comparisons) were averaged together (0-5, 6-10, 11-15, over-all mean) for statistical analyses at rest and during exercise. For descriptive data between males and females, an unpaired t-test was performed to determine if there were any gender differences on each variable of interest.

For the baseline rest and exercise energy expenditure trials, a two-way ANOVA with a repeated measure (Gender X EMS-Condition) was used to analyze the entire 15-minute measurement period for each variable (i.e., EE, RER, fat oxidation etc). When statistical differences were observed, a Tukey post-hoc procedure was used to determine where the difference occurred. When a significant difference was observed, Cohen's d Effect Size (ES) procedures were used to determine the magnitude. In addition, an unpaired t-test was performed to determine if there were any metabolic response differences between individuals who were below and above the median EMS maximal tolerable level for all subjects tested. Previously shown correlates (e.g. body weight, fat-free weight, aerobic capacity or $\mathrm{VO}_{2 \max }$ ) to resting $\mathrm{EE}$ plus new variables unique to this study (i.e., segmental lean tissue content including upper body lean, trunk lean, and lower body lean) were verified using correlation matrix procedures [6]. All tables are presented as means \pm SD. Graphs are presented as means \pm SEM. All statistics were set with an alpha level set at 0.05 for significance.

\section{Results}

\section{Physical demographics}

Table 1, Table 2, and Table 3 show the aerobic fitness, body composition, and free-living physical activity profile of the study subjects, respectively. Both male and female subjects had measured $\mathrm{VO}_{2}$ max values (Table 1) ranked according normative standards between the $75^{\text {th }}$ and $80^{\text {th }}$ percentile for each group's gender and age [19]. Relative to body weight in $\mathrm{ml} / \mathrm{kg} / \mathrm{min}$, males had greater aerobic capacities $\left(\mathrm{VO}_{2 \max }\right)$ than females $(\mathrm{p} \leq 0.003)$. 
Table 3: Subject's 24-HR Free-Living Physical Activity Profile Measured During Metabolic Testing Periods ${ }^{\dagger}$.

\begin{tabular}{|c|c|c|c|c|}
\hline Variable & $\begin{array}{l}\text { All Subjects } \\
(n=38)\end{array}$ & $\begin{array}{l}\text { Males } \\
(n=19)\end{array}$ & $\begin{array}{l}\text { Females } \\
(N=19)\end{array}$ & $\begin{array}{l}\text { Gender } \\
\text { Comparison }\end{array}$ \\
\hline $24 \mathrm{hr}$ kcals & $2881 \pm 637$ & $3021 \pm 733$ & $2741 \pm 506$ & NS \\
\hline $24 \mathrm{hr}$ kjoules $24 \mathrm{hr}$ step count & $12062 \pm 2667$ & $12648 \pm 3069$ & $11476 \pm 2119$ & NS \\
\hline $24 \mathrm{hr}$ kcals & $10630 \pm 4687$ & $10973 \pm 5766$ & $10285 \pm 3416$ & NS \\
\hline$\leq 3 \mathrm{METS}(\mathrm{min} / \%$ of $24 \mathrm{hr}$ period $)$ & $\begin{array}{l}1270 \pm 105 \\
(88.2 \pm 7.0)\end{array}$ & $\begin{array}{l}1264 \pm 117 \\
(87.8 \pm 8.1)\end{array}$ & $\begin{array}{l}1277 \pm 95 \\
(88.7 \pm 6.6)\end{array}$ & NS \\
\hline 3-6 METS ( $\mathrm{min} / \%$ of $24 \mathrm{hr}$ period) & $\begin{array}{l}159 \pm 98.0 \\
(11.0 \pm 6.8)\end{array}$ & $\begin{array}{l}166 \pm 112.0 \\
(11.6 \pm 7.8)\end{array}$ & $\begin{array}{l}151 \pm 84.2 \\
(10.5 \pm 5.8)\end{array}$ & NS \\
\hline 6-9 METS (min/\% of $24 \mathrm{hr}$ period) & $\begin{array}{l}7.5 \pm 11.9 \\
(0.5 \pm 0.1)\end{array}$ & $\begin{array}{l}4.9 \pm 8.0 \\
(0.3 \pm 0.6)\end{array}$ & $\begin{array}{l}10.2 \pm 14.6 \\
(0.7 \pm 1.0)\end{array}$ & NS \\
\hline$>9 \mathrm{METS}(\mathrm{min} / \%$ of $24 \mathrm{hr}$ period) & $\begin{array}{l}3.1 \pm 8.0 \\
(0.2 \pm 0.6)\end{array}$ & $\begin{array}{l}4.4 \pm 10.7 \\
(0.3 \pm 0.7)\end{array}$ & $\begin{array}{l}1.7 \pm 3.8 \\
(0.1 \pm 0.3)\end{array}$ & NS \\
\hline
\end{tabular}

All data mean \pm SD. ${ }^{\dagger}$ - Twenty-Four hour energy expenditure measurements were collected using BodyMedia Sensor Wear Pro Armband systems.

Body composition comparisons (Table 2 ) showed that males were significantly heavier $(p=0.0001)$, taller $(p=$ $0.0001)$, had a lower $\%$ body fat content $(p=0.0007)$, had greater fat-free weight content $(p=0.0001)$, greater intra- and extracellular water content $(p=0.0001)$, greater kilogram lean tissue content in the arms $(p=$ 0.0001 , trunk $(p=0.0001)$, and legs $(p=0.0001)$. Male and female percent body fat levels were $16.6 \% \pm 7.3$ ( $90^{\text {th }}$ percentile) and $25.7 \% \pm 7.7$ ( $40^{\text {th }}$ percentile) for their respective age and gender [22].

The 24-hr free living physical activity profile measured during the metabolic testing period showed no significant pattern differences comparing male and female subjects (Table 3 ). The results showed that both men and women combined had an average 24-hr total $\mathrm{EE}$ average of $2.881 \pm 637 \mathrm{kcals} /$ day $(12.062 \pm 2.667$ kjoules/day) or $37.7 \pm 8.3$ kcals per kilogram of total body weight or $47.9 \pm 10.6$ kcals per kilogram of fatfree weight. Twenty-four-hour step counts were 10.630 \pm 4.687 steps for all subjects combined. The subject's spent a majority of their activity time at $\leq 3$ METS or between $3-6$ METS ( $88.1 \%$ and $11.3 \%$, respectively) as required for the pre-testing metabolic activity criterion to assure baseline and treatment intervention metabolic measurements were not influenced by prior high intensity physical activity patterns.

\section{Test-Retest measurements}

The test-retest reliability data indicated there were no significant differences observed between repeat trials at rest or during exercise for either the shame or treatment conditions $\mathrm{EE}$ values measured between trials $A$ and $B$. The resting baseline energy expenditure between trial difference during the shame condition was $0.013 \mathrm{kcals} / \mathrm{min}$ or $1.2 \%$ difference for trial $A$ and trial $B$ (trial $A=1.215 \mathrm{kcal} / \mathrm{min}$, trial $B=1.228 \mathrm{kcals} / \mathrm{min}$; ICC $r$-value $=0.93$, SEE \pm 0.011 kcals). For the EMS treatment, trial $A$ and $B$ between trial difference was zero, when rounding to three decimal places (trial $A=1.458 \pm$ $0.326 \mathrm{kcals} / \mathrm{min}$ versus trial $B=1.458 \pm 0.335 \mathrm{kcals} / \mathrm{min}$ ). The ICC r-value was 0.94 with a SEE $\pm 0.019 \mathrm{kcal}$. For the shame condition, the between trial HR difference was $1.2 \mathrm{bpm}$ or $2.1 \%$. For the EMS activation trials, the between trial HR difference was $0.8 \mathrm{bpm}$ or $1.2 \%$. RER was identical between the repeat shame condition trials with a measured difference of only 0.006 or $0.7 \%$. For the EMS activation trials, the repeat trial difference was 0.01 or $2.4 \%$.

During the exercise repeated measurement trials, trials $A$ and $B$ for $V_{E}$, tidal volume, $\mathrm{VO}_{2}, E E$, and $H R$ showed very reproducible results under both the shame and treatment conditions. During the shame condition, trial $A$ versus $B$ differences ranged between a low of $1.0 \%$ to high of just $2.0 \%$ for all variables measured. During the EMS activation condition, between trial differences for all variables measured were $0.1 \%$ to $2.1 \%$. The post study power analysis profile showed that when a significant difference between the shame or EMS treatment condition was observed, the statistical power of the finding exceeded $90 \%$ for energy expenditure, $\mathrm{V}_{\mathrm{E}^{\prime}} \mathrm{VO}_{2^{\prime}}$, and HR.

\section{The effects of EMS activation on baseline energy expenditure and substrate utilization}

Predicted baseline EE at rest for both males and females combined are shown in (Figure 1). Comparison of each person's actual baseline EE at rest with the person's predicted value showed that $47 \%$ of the test subjects were above predicted norms and $53 \%$ below showing a normal resting EE distribution for the entire study group. As a result, there was not a significant difference between predicted $(1.200 \mathrm{kcals} / \mathrm{min}, \mathrm{SEM}=0.009)$ and actual resting EE values (1.221 kcals/min, $\mathrm{SEM}=0.039$ ). Comparing the effects of EMS activation on resting baseline EE with each person's predicted value showed that $76 \%$ of the subjects were now showing an actual energy expenditure value above their predicted value ( $p$-value $=0.002$ ). In addition, $100 \%$ of the subjects showed higher EE at rest during the EMS activation trial compared to the actual shame treatment period.

As a result of the EMS activation, EE per minute (Table 4) significantly increased $19.4 \%$ during the EMS activation trial compared to the shame condition (No EMS 


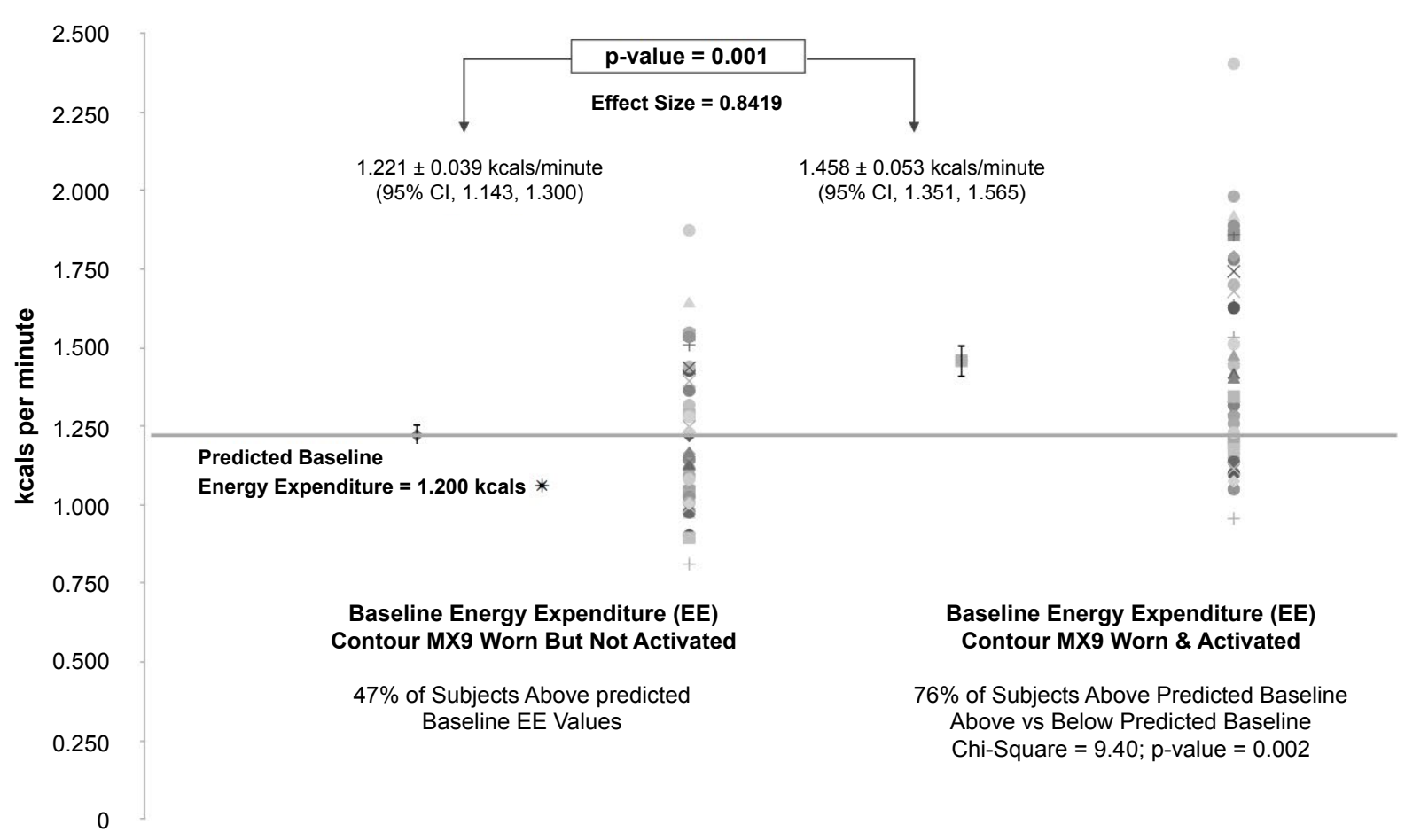

No significant diffrence observed between predicted baseline energy expenditure data and the measured baseline energy expenditure with the Contour MX9 worn but not activated.

Figure 1: The Metabolic Effect of Same Versus EMS on Baseline Energy Expenditure Compared to Predicted RMR Values.

Table 4: Effects of EMS Activation on Resting Baseline Energy Expenditure and Substrate Utilization.

\begin{tabular}{|c|c|c|c|c|c|c|c|c|}
\hline & \multicolumn{2}{|c|}{$\begin{array}{l}\text { VO } \mathrm{O}_{2} \text { Uptake } \\
\text { (liters/min) }\end{array}$} & \multicolumn{2}{|c|}{$\begin{array}{l}\text { Energy Expenditure } \\
\text { (kcal/min) }\end{array}$} & \multicolumn{2}{|c|}{$\begin{array}{l}\text { Heart Rate } \\
\text { (beats/min) }\end{array}$} & \multicolumn{2}{|c|}{$\begin{array}{l}\text { RER } \\
\left(\mathrm{VCO}_{2} / \mathrm{VO}_{2}\right)\end{array}$} \\
\hline & NO EMS ${ }^{*}$ & $\begin{array}{l}\text { Contour } \\
\mathrm{MX9}^{+}\end{array}$ & NO EMS ${ }^{*}$ & $\begin{array}{l}\text { Contour } \\
\mathrm{MX9}^{\dagger}\end{array}$ & NO EMS ${ }^{*}$ & $\begin{array}{l}\text { Contour } \\
\mathrm{MX9}^{\dagger}\end{array}$ & NO EMS ${ }^{*}$ & $\begin{array}{l}\text { Contour } \\
\mathrm{MX9}^{+}\end{array}$ \\
\hline Mean & 0.258 & 0.303 & 1.221 & 1.458 & 56 & 64 & 0.77 & 0.83 \\
\hline Std Dev & 0.051 & 0.067 & 0.238 & 0.325 & 10 & 11 & 0.03 & 0.06 \\
\hline Upper 95\% & 0.269 & 0.318 & 1.3 & 1.565 & 60 & 68 & 0.78 & 0.84 \\
\hline Lower 95\% & 0.246 & 0.287 & 1.143 & 1.351 & 53 & 60 & 0.76 & 0.81 \\
\hline$\%$ difference & • & $17.4 \%$ & • & $19.4 \%$ & $\bullet$ & $14.3 \%$ & • & $7.8 \%$ \\
\hline \multirow[t]{3}{*}{ Effect Size } & - & 0.763 & $\cdot$ & 0.842 & $\cdot$ & 0.762 & • & 1.333 \\
\hline & \multicolumn{2}{|c|}{$\begin{array}{l}\text { Fat Utilization } \\
\text { (kcals/min) }\end{array}$} & \multicolumn{2}{|c|}{$\begin{array}{l}\text { Fat Utilization } \\
\text { (grams/min) }\end{array}$} & \multicolumn{2}{|c|}{$\begin{array}{l}\text { CHO Utilization } \\
\text { (kcals/min) }\end{array}$} & \multicolumn{2}{|c|}{$\begin{array}{l}\text { CHO Utilization } \\
\text { (grams/min) }\end{array}$} \\
\hline & NO EMS ${ }^{*}$ & $\begin{array}{l}\text { Contour } \\
\text { MX9 }\end{array}$ & NO EMS ${ }^{*}$ & $\begin{array}{l}\text { Contour } \\
\text { MX9 }\end{array}$ & NO EMS ${ }^{*}$ & $\begin{array}{l}\text { Contour } \\
\text { MX9 }^{\dagger}\end{array}$ & NO EMS ${ }^{*}$ & $\begin{array}{l}\text { Contour } \\
\text { MX9 }\end{array}$ \\
\hline Mean & 0.936 & 0.886 & 0.104 & 0.098 & 0.285 & 0.572 & 0.071 & 0.143 \\
\hline Std Dev & 0.257 & 0.290 & 0.029 & 0.032 & 0.146 & 0.286 & 0.037 & 0.071 \\
\hline Upper 95\% & 1.02 & 0.981 & 0.113 & 0.109 & 0.333 & 0.666 & 0.083 & 0.167 \\
\hline Lower 95\% & 0.852 & 0.79 & 0.095 & 0.088 & 0.237 & 0.478 & 0.059 & 0.12 \\
\hline$\%$ difference & $\cdot$ & $-5.3 \%$ & $\bullet$ & $-5.8 \%$ & $\bullet$ & $100.7 \%$ & $\cdot$ & $101.4 \%$ \\
\hline Effect Size & - & 0.183 & - & 0.197 & - & 1.329 & - & 1.331 \\
\hline
\end{tabular}

${ }^{\dagger}=\mathrm{p}$-value $=0.0001$ comparing no EMS versus EMS actively on. ${ }^{*}$ Contour MX9 Belt worn but no EMS activation $=$ Same data measurements.

$=1.221 \pm 0.238$, Contour MX9 $1.458 \pm 0.325 ;$ p-value $0.001)$. In accordance with these findings, oxygen uptake, heart rate, and RER significantly increased during the EMS activation trial compared to the shame treatment $17.4 \%, 14.3 \%$ and $7.8 \%$ ( $p$-value $=0.001)$, respectively. With the increase in metabolic demand during the EMS activation period, the increase resting RER values led to a significant increase in \%CHO oxidation at rest during the EMS trial compared to the shame treatment. This increase led to a doubling of both kcals/ $\min$ and grams/min $\mathrm{CHO}$ use ( $p$-value $=0.001)$. However, because of a significantly larger increase in oxygen uptake in combination with the fact that the RER increase remained below the 0.85 cross-over point where a person shifts from fat to primarily carbohydrate usage, a non-significant decline in fat oxidation in kcals and grams per minute was observed equal to $-5.3 \%$ and $-5.8 \%$ respectively. There were no gender differences 
in metabolic responses between males and females for oxygen uptake and energy expenditure during the EMS activation trials compared to the shame measurement period.

When the test subjects were subdivided into either a low $(21.8 \% \pm 1.9$; Males $n=9$, Female $n=10)$ versus high $(28.2 \% \pm 4.2$; Males $n=10$, Female $n=9)$ tolerance EMS groups, there were no significant differences in the effects EMS activation had on enhancing EE compared to the shame treatment period (Low Tolerance EE $=19 \%$ increase and High Tolerance EE $=20 \%$ increase above baseline).

Based on the correlation matrix data looking at which factors most correlated with the study group's baseline metabolic EE profile, both total fat-free weight $(r$-value $=0.88, p$-value $=0.0001)$ and trunk lean tissue weight $(r$-value $=0.89, p$-value $=0.0001$ ) were the most important factors affecting a subject's EE at rest. In accordance with these findings, there were no significant differences observed in fat-free weight (Low EMS Tolerance $=60.1 \pm 14.4 \mathrm{~kg}$ versus High EMS Tolerance $=60.3$ $\pm 16.4 \mathrm{~kg}$ ) or trunk lean tissue (Low EMS Tolerance = $26.8 \pm 6.5 \mathrm{~kg}$ versus High EMS Tolerance $=26.9 \pm 7.4 \mathrm{~kg}$ ) distributions between the two different EMS tolerance groups.

\section{The effects of EMS activation on cardiorespiratory and metabolic response during treadmill walking}

According to the steady exercise trial results (Table 5), walking at $3.5 \mathrm{mph}$ up a $5 \%$ grade resulted in a steadystate exercise intensity equal to $49.1 \%$ and $65.4 \%$ of $\mathrm{VO}_{2}$ max and max HR, respectively. At this relative exercise intensity level and using each subject's actual baseline MET (metabolic equivalent) level, subjects walked at an exercise intensity of 5.56 METS during the shame treatment periods. Correspondingly, EE during the shame treatment period equaled $7.948 \pm 1.511 \mathrm{kcals} / \mathrm{min}$ while oxygen uptake was $1.644 \pm 0.312 \mathrm{liters} / \mathrm{min}$. During the
EMS activation trial while walking at $3.5 \mathrm{mph}$ up a $5 \%$ grade, similar to the effects observed during rest, EMS activation significantly changed for ventilation $+9.6 \%$ $(p=0.0001)$, respiration rate $+15.5 \%(p=0.0001)$, tidal volume $-5.6 \%(p=0.0001), \mathrm{VO}_{2}+4.6 \%(p=0.0001)$, EE $+4.4 \%(p=0.0001), R E R+1.3 \%(p \leq 0.02)$, and HR +8.3\% $(p=0.0001)$. As a result, the cardiorespiratory demand of the EMS activation trial was $51.4 \%$ and $70.9 \%$ of $\mathrm{VO}_{2}$ max and max heart rate, respectively. In contrast to the resting substrate oxidation changes occurring during the EMS activation trial compared to the shame treatment period, EMS activation during light to moderate exercise levels produced a greater fat oxidation by $10.4 \%$ ( $p$-value $=0.0001$ ) with only a slight decline in carbohydrate oxidation (-1.4\% NS).

\section{Discussion}

The results of this study indicated that the addition of abdominal EMS activation significantly increased both metabolic and cardiorespiratory demand at rest and while walking at $3.5 \mathrm{mph}$ at a $5 \%$ grade. These effects were similar in both men and women while also being independent of the EMS stimulation intensity a given person could tolerate during the intervention period.

These results agree with previous studies showing that EMS activation of large leg muscles significantly improved both the metabolic and cardiovascular responses during and following the activation period [14,19-21]. In the current study, EMS activation increased oxygen uptake and EE by $17.4 \%$ (ES: $0.76=$ large) and 19.4\% (ES: $0.94=$ large) compared to the same treatment at supine rest, respectively. Correspondingly, HR increased $14.3 \%$ (ES: $0.76=$ large) and RER also shifted from a shame value of 0.77 to a EMS stimulate value of 0.83 . As a consequence, fat utilization during rest declined slightly (NS) while $\mathrm{CHO}$ use significantly increased ( $p=0.0001$; ES: $1.333=$ large to very large). These findings are supported by two previous studies showing that lower body low frequency EMS activation during rest can significantly

Table 5: The Cardiorespiratory Effects of EMS Activation during Treadmill Walking (3.5 mph, 5\% grade).

\begin{tabular}{|c|c|c|c|c|c|c|}
\hline & \multicolumn{2}{|c|}{ Ventilation (liters/min) } & \multicolumn{2}{|c|}{ Respiration Rate (breaths/min) } & \multicolumn{2}{|c|}{ Tidal Volume (liters/min) } \\
\hline & NO EMS ${ }^{\star}$ & Contour MX9 ${ }^{\dagger}$ & NO EMS ${ }^{\star}$ & Contour MX9† & NO EMS ${ }^{*}$ & Contour MX9 ${ }^{\dagger}$ \\
\hline Mean & 42.6 & 46.7 & 29.6 & 34.2 & 1.465 & 1.383 \\
\hline Std Dev & 6.9 & 7.2 & 3.6 & 4.7 & 0.248 & 0.116 \\
\hline Upper 95\% & 44.9 & 49.1 & 30.8 & 35.7 & 1.546 & 1.449 \\
\hline Lower 95\% & 40.4 & 44.4 & 28.4 & 32.6 & 1.383 & 1.316 \\
\hline$\%$ difference & • & $9.6 \%$ & $\cdot$ & $15.5 \%$ & • & $-5.6 \%$ \\
\hline \multirow[t]{3}{*}{ Effect Size } & • & 0.582 & • & 1.108 & • & 0.451 \\
\hline & \multicolumn{2}{|c|}{ VO $_{2}$ Uptake (liters/minute) } & \multicolumn{2}{|c|}{ Energy Expenditure (kcal/min) } & \multicolumn{2}{|c|}{ Heart Rate (beats/min) } \\
\hline & NO EMS ${ }^{*}$ & Contour MX9 ${ }^{\dagger}$ & NO EMS ${ }^{*}$ & Contour MX9 ${ }^{\dagger}$ & NO EMS ${ }^{*}$ & Contour MX9 ${ }^{\dagger}$ \\
\hline Mean & 1.644 & 1.72 & 7.948 & 8.301 & 121 & 131 \\
\hline Std Dev & 0.312 & 0.305 & 1.511 & 1.473 & 16 & 17 \\
\hline Upper 95\% & 1.747 & 1.82 & 8.444 & 8.785 & 127 & 137 \\
\hline Lower 95\% & 1.541 & 1.619 & 7.451 & 7.817 & 116 & 125 \\
\hline$\%$ difference & $\cdot$ & $4.6 \%$ & $\cdot$ & $4.4 \%$ & • & $8.3 \%$ \\
\hline Effect Size & - & 0.246 & - & 0.031 & - & 0.606 \\
\hline
\end{tabular}

${ }^{\dagger}=\mathrm{p}$-value $=0.0001$ comparing no EMS versus EMS actively on. ${ }^{*}$ Contour MX9 Belt worn but no EMS activation $=$ Same data measurements. 
enhance $E E$, carbohydrate oxidation, and whole-body glucose uptake using the euglycemic clamp technique in males by increasing anaerobic metabolism [25-27].

Similar to the current study, Kemmler, et al. [7] used a stimulation frequency of $85 \mathrm{~Hz}$ with $4 \mathrm{~s}$ activation period during whole body EMS activation with various squat exercises. EE measured by indirect calorimetry during exercise with and without EMS activation showed significantly greater EE by $17 \%$ during EMS activation ( $p=$ 0.008). In contrast to these findings, Hayter, et al. [6] did not show a significant increase in oxygen uptake, HR, and RER values comparing two different commercially available EMS units (Abtronic and Feminique). However, the EMS activation protocol was distinctly different from the current study and the previously discussed studies in that both a low frequency and low intensity settings ( 1 second rest, 1 second on) were used in the study by Hayter, et al. [6].

In contrast, the current study's EMS activation level was set at $85 \mathrm{~Hz}$ for 6 seconds during the contraction phase in order to produce high muscular tension and activate both slow and fast twitch muscles. Also, the stimulation intensity in the current study was set at the highest tolerable stimulation level possible for each individual subject. As a result, each subject reported both during the accommodation trial and the measurement trials, the EMS settings produced a strong noticeable muscle contraction throughout the activation period. Subjects also often reported feeling the EMS activation caused their body temperature to increase. However, we did not measure body temperature, we couldn't verify this reported subject response. Thus, it is possible that the lack of response in the Hayter [6] study compared to the current study and others was due to an inadequate stimulation protocol. Without an adequate EMS stimulation in both intensity and frequency, one would not expect a significant effect on neuromuscular firing for activating both slow and fast twitch muscle needed to increase metabolic demand while at rest.

In the current study, the baseline and EMS activation test-retest results showed the shame and EMS treatment conditions were highly reproducible. For example, the baseline shame resting energy expenditure difference was only $1.2 \%$ between trial $A$ and trial $B$ with ICC $r$-value $=0.93$, SEE \pm 0.011 . For the EMS activation test-retest trials, the measured energy expenditure values were almost identical for both trial $A$ and $B$ (Trial $A=$ $1.458 \pm 0.326$; Trial $B=1.458 \pm 0.335 \mathrm{kcals} / \mathrm{min})$. Similar ICC $r$-values were observed as measured under the EMS condition ( $r$-value $=0.94$. SEE \pm 0.019 ). In addition, comparing the baseline resting EE values with each person's predicted resting value, one can see in Figure 1 that during the shame condition, resting EE was not significantly different for the mean of all subjects (Predicted Resting Value: $1.200 \mathrm{kcals} / \mathrm{min}$ versus Shame Treatment; 1.221 kcals/min). In contrast, the EMS activated group mean of $1.458 \pm 0.053$ was $21.5 \%$ greater than predicted values. As a result, during the EMS activation, $76 \%$ of subjects exceeded their respective predict resting value compared to just $47 \%$ under the shame condition ( $p=$ 0.002 ). The ES was 0.8419 which suggests a strong EMS effect on resting EE. The response was similar for both men and women. It is important to point out that for the EMS stimulated increase in RER and $\mathrm{CHO}$ oxidation rates, the effect size was double in males compared to female subjects (Male ES = 1.94 exceptionally large; Female ES $=0.94$ large) .

An unexpected finding in this study was related to the effects stimulation intensity had on EE. According to our results, energy expenditure increases were independent of the absolute EMS stimulation intensity a person could tolerate. For example, using the median EMS stimulation intensity value for all subjects, we divided the subjects in either a low (Intensity $=21.8 \pm$ $1.9 \%$ of the units maximum output) or high (Intensity $=28.0 \pm 4.2 \%$ of the units maximum output) EMS tolerance stimulation group. Comparing the two groups, the EE values were very similar (Low Tolerance $=1.483 \mathrm{kcals}$ versus High Tolerance $=1.432$ kcals) despite significantly different absolute stimulation intensities. However, it is important to point that the EMS intensity level was set for all subjects at each person's respective highest possible tolerance level despite the individual differences in absolute unit intensity. In correspondence with these findings, energy expenditure during EMS activation at rest was significantly related to both the amount of total FFW and trunk lean tissue in $\mathrm{kg}(\mathrm{p}=0.0001)$. Thus, these findings simply imply that each person has an individualized EMS activation threshold point to completely active abdominal trunk muscles for enhancing his or her metabolic responses to EMS activation.

During exercise $\mathrm{V}_{\mathrm{E}}$ (9.6\%; ES: 0.5816 = strong), respiration rate (15.5\%; ES: 1.1084 = very large), oxygen uptake (4.6\%; ES: 0.2464 = small), energy expenditure (4.4\%; ES: 0.030 = very small) and HR (8.3\%; ES: 0.606 = medium) significantly increased compared to walking at $3.5 \mathrm{mph}$ up a $5 \%$ grade during the shame condition. Thus, cardiorespiratory demand increased during the EMS activation trial compared to the shame treatment. In contrast to the resting substrate oxidation declines in fat oxidation that occurred during the EMS activation trial, EMS activation during light to moderate exercise levels significantly increased fat oxidation in kcals/min by $10.4 \%$ ( $p$-value $=0.0001$; ES: $0.0200=$ small). During exercise, EMS activation only slightly increased the exercising RER value and that small increase was less than the absolute increase in oxygen uptake. As a consequence, both the absolute fat grams and kcals/min of fat oxidation significantly increased slightly ( $p$-value $=0.0001$ : ES: $0.0200=$ small) during exercise with EMS activation.

The steady-state exercise intervention was selected to represent what is normally suggested by manufactur- 
ers who promote their devices to be used while walking or working around the house. To date, there are no other studies that have looked at the effects of EMS activation during steady-state endurance exercise. However, these results suggest that the addition EMS use during light to moderate steady-state exercise may enhance a person's metabolic and cardiorespiratory demand.

In conclusion, future studies should determine if the chronic use of EMS in combination with low to moderate intensity steady-state exercise can significantly enhance the training adaptations normally observed during endurance training such as improvements in fat oxidation, glucose tolerance and insulin sensitivity, and possibly enhance weight loss while providing enhancements in abdominal muscle strength and endurance. And finally, because these results showed that ventilation, respiration rate, and tidal volume all were significantly affected by EMS activation of the abdominal muscles, future studies should determine if EMS activation added to an endurance training program can have any positive benefits on the respiratory function of patients with chronic pulmonary obstructive disease.

\section{Acknowledgments}

Special thanks to Laurie Schubert, Ph.D. and Richard Hickey, III for their assistance in the data collection.

\section{Funding}

Funding was provided by a grant from Contour Technology, Minneapolis, MN.

\section{Conflict of Interest Statement}

There are no known conflicts of interest.

\section{References}

1. Banerjee DP (2011) Can Electrical Muscle Stimulation of the Legs Produce Cardiovascular Exercise? Clinic Experiment Cardiol 2: 134.

2. Currier DP, Belanger M, Mann R, Stein RB, Wheeler GD, et al. (2000) Electrical stimulation: can it increase muscle strength and reverse osteopenia in spinal cord injured individuals? Arch Phys Med Rehabil 81: 1090-1098.

3. Currier DP, Mann R (1983) Muscular strength development by electrical stimulation in healthy individuals. Phys Ther 63: 915-921.

4. Harris S, LeMaitre JP, Mackenzie G, Fox KA, Denvir MA (2003) A randomised study of home-based electrical stimulation of the legs and conventional bicycle exercise training for patients with chronic heart failure. Eur Heart J 24: 871-878.

5. Poole RB, Harrold CP, Burridge JH, Byrne CD, Holt RIG (2005) Electrical muscle stimulation acutely mimics exercise in neurologically intact individuals but has limited clinical benefits in patients with type 2 diabetes. Diabetes Obes Metab 7: 344-351.

6. Hayter TL, Coombes JS, Knez WL, Brancato TL (2005) Effects of electrical muscle stimulation on oxygen consumption. J Strength Cond Res 19: 98-101.

7. Kemmler W, Schliffka R, Mayhew JL, Stengel von S (2010) Effects of whole-body electromyostimulation on resting metabolic rate, body composition, and maximum strength in postmenopausal women: the Training and ElectroStimulation Trial. J Strength Cond Res 24: 1880-1887.

8. Porcari J, Miller J, Cornwell K, Foster C (2005) The effects of neuromuscular electrical stimulation training on abdominal strength, endurance, and selected anthropometric measures. J Sports Sci Med 4: 66-75.

9. Porcari JP, McLean KP, Foster C, Kernozek T, Crenshaw $B$, et al. (2002) Effects of electrical muscle stimulation on body composition, muscle strength, and physical appearance. J Strength Cond Res 16: 165-172.

10. Vandarakis D, Salacinski AJ, Broeder CE (2013) A comparison of COSMED metabolic systems for the determination of resting metabolic rate. Res Sports Med 21: 187-194.

11. Vanderthommen M, Duchateau J (2007) Electrical Stimulation as a Modality to Improve Performance of the Neuromuscular System. Exerc Sport Sci Rev 35: 180-185.

12. Wakeling JM, Lee SS, Arnold AS, de Boef Miara M, Biewener AA (2012) A muscle's force depends on the recruitment patterns of its fibers. Ann Biomed Eng 40: 1708-1720.

13. Ward AR, Shkuratova N (2002) Russian electrical stimulation: the early experiments. Phys Ther 82: 1019-1030.

14. Banerjee P, Caulfield B, Crowe L, Clark A (2005) Prolonged electrical muscle stimulation exercise improves strength and aerobic capacity in healthy sedentary adults. J Appl Physiol 99: 2307-2311.

15. Maffiuletti NA, Dugnani S, Folz M, Di Pierno E, Mauro F (2002) Effect of combined electrostimulation and plyometric training on vertical jump height. Med Sci Sports Exerc 34: 1638-1644.

16. Maffiuletti NA, Zory R, Miotti D, Pellegrino MA, Jubeau M, et al. (2006) Neuromuscular Adaptations to Electrostimulation Resistance Training. Am J Phys Med Rehabil 85: 167-175.

17. Maggioni MA, Cè E, Rampichini S, Ferrario M, Giordano G, et al. (2010) Electrical stimulation versus kinesitherapy in improving functional fitness in older women: A randomized controlled trial. Arch Gerontol Geriatr 50: 19-25.

18. Malatesta D, Cattaneo F, Dugnani S, Maffiuletti NA (2003) Effects of electromyostimulation training and volleyball practice on jumping ability. J Strength Cond Res 17: 573-579.

19. Banerjee P, Caulfield B, Crowe L, Clark AL (2009) Prolonged electrical muscle stimulation exercise improves strength, peak VO2, and exercise capacity in patients with stable chronic heart failure. J Card Fail 15: 319-326.

20. Banerjee P, Clark A, Witte K, Crowe L, Caulfield B (2005) Electrical stimulation of unloaded muscles causes cardiovascular exercise by increasing oxygen demand. Eur J Cardiovasc Prev Rehabil 12: 503-508.

21. Crowe L, Caulfield B (2011) Pushing out the limits of electrical stimulation. A case study in the aggressive use of an alternative to voluntary exercise. BMJ Case Rep 2011.

22. Broeder CE, Burrhus KA, Svanevik LS, Volpe J, Wilmore JH (1997) Assessing body composition before and after resistance or endurance training. Med Sci Sports Exerc 29: 705-712.

23. Thompson W, Gordon N, Pescatello L (2009) ACSM's Guidelines for Exercise Testing and Prescription. ( $8^{\text {th }}$ edn), Lippincott Williams \& Wilkins, Baltimore (MD).

24. Nieman DC (2003) Exercise Testing and Prescription. (5 $5^{\text {th }}$ edn), McGraw-Hill, Boston (MA).

25. Tanaka H, Monahan KD, Seals DR (2001) Age-predicted maximal heart rate revisted. J Am Coll Cardiol 37: 153-156. 
26. Hamada T, Sasaki H, Hayashi T, Moritani T, Nakao K (2003) Enhancement of whole body glucose uptake during and after human skeletal muscle low-frequency electrical stimulation. J Appl Physiol (1985) 94: 2107-2112.
27. Hamada T, Hayashi T, Kimura T, Nakao K, Moritani T (2004) Electrical stimulation of human lower extremities enhances energy consumption, carbohydrate oxidation, and whole body glucose uptake. J Appl Physiol (1985) 96: 911-916. 